\title{
A neuro-fuzzy approach for tracking maximum power point of photovoltaic solar system
}

\author{
Aouatif Ibnelouad ${ }^{1}$, Abdeljalil Elkari², Hassan Ayad ${ }^{3}$, and Mostafa Mjahed ${ }^{4}$ \\ ${ }^{1,2}$ Department of Applied Physics. Laboratory of Electrical Systems and Telecommunications, Cadi Ayyad University, \\ Faculty of Sciences and Technologies, Marrakech, Morocco. \\ ${ }^{3,4}$ Department of Mathematics and Systems, Royal School of Aeronautics, Marrakech, Morocco.
}

\begin{tabular}{l} 
Article Info \\
\hline Article history: \\
Received Nov 30, 2020 \\
Revised Mar 15, 2021 \\
Accepted Apr 20, 2021 \\
\hline Keywords: \\
Artificial neural networks \\
Fuzzy logic controller \\
Maximum power point tracking \\
Neuro-fuzzy \\
Photovoltaic system
\end{tabular}

Article Info

Article history:

Received Nov 30, 2020

Revised Mar 15, 2021

Keywords

Artificial neural networks

Fuzzy logic controlle

Neuro-fuzzy

\begin{abstract}
This work presents a hybrid soft-computing methodology approach for intelligent maximum power point tracking (MPPT) techniques of a photovoltaic (PV) system under any expected operating conditions using artificial neural network-fuzzy (neuro-fuzzy). The proposed technique predicts the calculation of the duty cycle ensuring optimal power transfer between the PV generator and the load. The neuro-fuzzy hybrid method combines artificial neural network (ANN) to direct the controller to the region where the MPP is located with its reference voltage estimator and its block of neural order. After that, the fuzzy logic controller (FLC) with rule inference begins to establish the photovoltaic solar system at the MPP. The obtained simulation results using MATLAB/simulink software for the proposed approach compared to ANN and the perturb and observe $(\mathrm{P} \& \mathrm{O})$, proved that neuro-fuzzy approach fulfilled to extract the optimum power with pertinence, efficiency and precision.
\end{abstract}

This is an open access article under the CC BY-SA license.

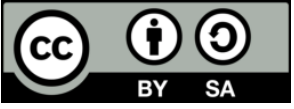

\section{Corresponding Author:}

Aouatif Ibnelouad

Department of Applied Physics, Laboratory of Electrical Systems and Telecommunications

Cadi Ayyad University, Faculty of Sciences and Technologies

112 Boulevard Abdelkrim Al Khattabi, Marrakech 40000, Morocco

Email: aouatif.ibnelouad@ced.uca.ma

\section{INTRODUCTION}

Energy production is a challenge of great importance for the years to come. The energy needs of industrialized societies as well as developing countries are steadily increasing. This production has tripled since the 1960s to the present day. All global energy production comes from fossil sources. The consumption of these sources gives rise to greenhouse gas emissions and therefore an increase in pollution. In addition, the excessive consumption of natural resource stocks reduces the reserves of this type of energy in a dangerous way for future generations. Renewable energies such as wind power, solar energy, biomass energy and hydropower are promising solutions to compete with mass energy sources such as fossil and nuclear energy. Renewable energy means energy from the sun, wind, earth heat, water or biomass. Unlike fossil fuels, renewable energies are energies with unlimited resources. Solar radiation is distributed over the entire surface of the earth; its density is not great and causes no conflict between countries unlike oil. Among these resources, solar energy is considered today as one of the most reliable renewable energies, daily and respectful of the environment the source [1], [2]. Photovoltaic energy has nowadays an increased importance in electrical power applications, since it is considered as an essentially inexhaustible and broadly available energy resource [3]. 
Photovoltaic (PV) cells are usually manufactured of semiconductor materials capable of converting the energy of sunlight at certain wavelength to DC electricity. When sunlight hits the surface of a PV cell, the semiconductor material allowing electrons to move from the valence band to the conduction band absorbs some of the photons' energy. The electrons are then ready to flow in a closed-path circuit carrying electrical energy to the load. Cells are usually connected in series to form a PV module. The modules are connected in different series and parallel topologies to reach the desired voltage and current level [4]. The photovoltaic system consists of a photovoltaic panel with a power interface and a load. A simple DC / DC converter circuit (Boost) is used as interface between photovoltaic panel PV and load. This DC/DC converter intended to transfer maximum energy from photovoltaic panel PV to load and to ensure our load closer to the MPP. In order to improve the efficiency of the photovoltaic generator (PV), in other words maximize the power delivered to the load connected to the terminals of the generator, several criteria for optimizing the efficiency of the photovoltaic system were applied and techniques were followed for good adaptation and high efficiency [5], [6]. Among these techniques is the technique of Pursuit of the Power Point Maximal or "Maximum Power Point Tracker, MPPT" [7, 8], several methods are mentioned in the bibliography: the P\&O method is a widely used in practice due to its simplicity and requires only measures voltage and current of the PV module [9]. However, this algorithm can oscillate around the Maximum Power Point (MPP) under sudden sunlight changes [10]-[12]. Recently, several researchers for photovoltaic systems track the maximum power by intelligent MPPT techniques such as artificial neural network (ANN) and Fuzzy logic controller. The artificial neural network (ANN) techniques are being utilized for photovoltaic applications, principally because of their symbolic reasoning, flexibility and explanation capabilities that are useful to deal with strong nonlinearities and complex systems [13]. The use of artificial neural network (ANN) in photovoltaic systems has been considered by several researchers [14]-[16]. Fuzzy logic controller has been considered as an efficient and effective tool in managing uncertainties and nonlinearities of systems [17]. A fuzzy logic controller is generally designed in the light of experience and expert knowledge [17]-[20].

This paper presents a novel MPPT methodology based on a hybrid model between two important intelligent MPPT methods. This hybrid model: Neuro-fuzzy approach defines of multi-layered feed forwarded artificial neuron network and the inference-based table of the fuzzy logic controller. The architecture of the artificial neural network composed of three layers: inputs, hidden and output layers. The proposed intelligent MPPT method artificial neural network is to direct the controller to the region where the MPP is located with its reference voltage estimator and its block of neural order. After that, the fuzzy logic with rule inference begins to establish the photovoltaic solar system at the maximum power point (MPP). The hybrid model: Neuro-fuzzy approach aims to decrease the complexity of the photovoltaic solar system and to extract the maximum power at the minimum time with pertinence and efficiency under any weather conditions compared to the single ANN and conventional MPPT method P\&O. To develop the Neuro-Fuzzy approach method, this work is structured as follows: Section 2 overview of photovoltaic solar system by making a focus on the model, the characteristics of a PV module and presents the goal of DC/DC converter. Section 3 describes a classical MPPT method is widely used at the literature P\&O. Section 4 presents the proposed approach Neuro-Fuzzy. Section 5 describes the detail simulation results comparing the novel approach with the single ANN and the P\&O MPPT method after that it presents the comparison of novel MPPT methodology neuro-fuzzy in state of the art, followed by the conclusion in Section 6.

\section{OVERVIEW OF PHOTOVOLTAIC SOLAR SYSTEM}

The global of the studied system shows in Figure 1, composed of a $305 \mathrm{~W}$ photovoltaic solar generator connected to a power electronic element. This element consists of a DC-DC converter that assures impedance adaptation between the photovoltaic solar generator and the load resistive by tracking the maximum power by the neuro-fuzzy approach network. In the following paragraphs, all the blocks of the photovoltaic solar PV system are described in detail. 


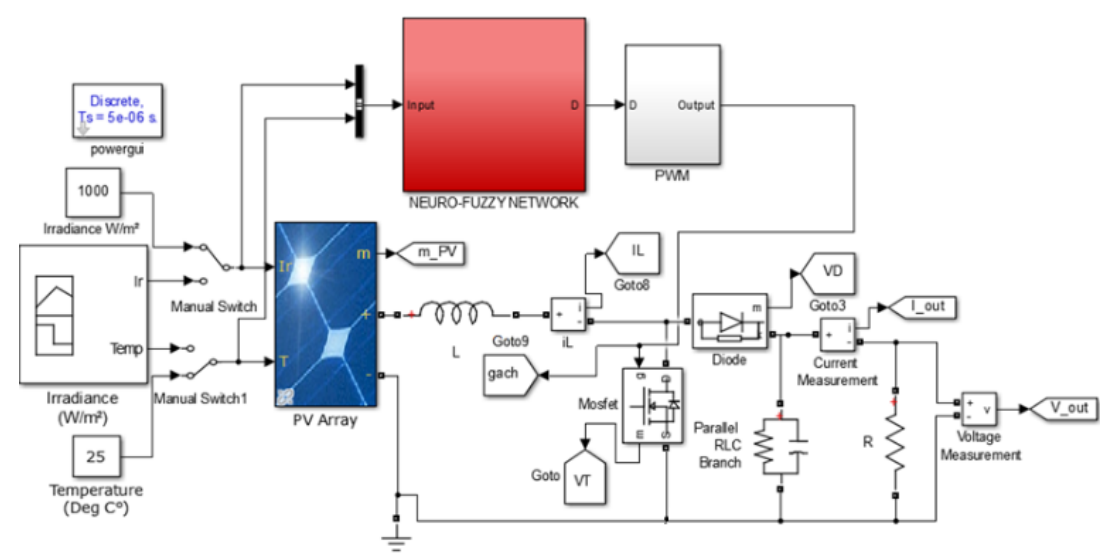

Figure 1. Overview of the neuro-fuzzy approach network MPPT photovoltaic solar PV system

\subsection{Photovoltaic solar module}

The PV solar module used in this study consists of polycrystalline silicon solar cells electrically. Its main electrical specifications are shown in Table 1.

Table 1. Technical data of the model manufacturer sunpower SPR-305E.

\begin{tabular}{lc}
\hline Maximum Power (W) & 305 \\
\hline Open circuit voltage Voc (V) & 64.2 \\
Short-circuit current Isc (A) & 5.96 \\
Current at maximum power point Imp(A) & 5.58 \\
Voltage at maximum power point Vmp (V) & 54.7 \\
\hline
\end{tabular}

\subsection{Simulation model of a PV generator}

The mathematical models of the PV generator are defined in the following equations. Figure 2 shows the equivalent circuit of a solar cell using a single diode model due to accuracy for photovoltaic (PV) studies. A solar panel is composed of several photovoltaic cells employing series or parallel or series-parallel external connections.

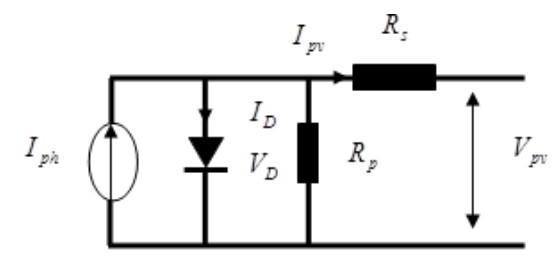

Figure 2. Equivalent circuit of solar cell

The following equations describe the I-V characteristic of a solar cell [21]:

$$
\begin{aligned}
& I_{p h}=I_{d}+I_{R p}+I_{p v} \\
& I_{d}=I_{o}\left[e^{\left(V_{p v}+\frac{I_{P V} R_{S}}{a V_{T}}\right)}-1\right] \\
& V_{T}=\frac{N_{S} k T}{q} \\
& I_{R p}=\frac{\left(v_{p v}+\left(I_{p v} R_{S}\right)\right)}{R_{p}}
\end{aligned}
$$




$$
I_{p h}=\left(\frac{G}{G_{n}}\right)\left(I_{s c}+\left(k_{i} \Delta T\right)\right)
$$

After combination of the equations above, the generalize current voltage equation of a photovoltaic (PV) model is:

$$
I_{p v}=I_{p h}-I_{o}\left(e^{\left(v_{p v}+\frac{I_{p v} R_{S}}{a V_{T}}\right)}-1\right)-\left(V_{p v}+\frac{I_{p v} R_{S}}{R p}\right)
$$

Where:

$I_{p v}$ : The PV current; $I_{p h}$ : has a linear relationship with light intensity and varies with temperature variations; $\mathrm{I}_{\mathrm{d}}$ : The Shockley diode equation (A); $I_{o}$ : The saturated reverse current; " $a$ ": the constant known as the diode ideality factor; $V_{T}$ : The thermal voltage associated with the cells; $\mathrm{N}_{\mathrm{s}}$ : The number of cells connected in series; " $q$ ": The charge of the electron; K: The Boltzmann constant; $T$ : The absolute temperature of the $\mathrm{p}-\mathrm{n}$ junction; $I_{s c}$ : The short circuit current; $K_{i}$ : The coefficient of short-circuit current variation with temperature; $G$ : The light intensity. $R_{s}$ and $R_{p}$ : are the series and parallel equivalent resistances of the solar panel respectively; $\Delta T=T-T_{n}$ : The deviation from standard temperature.

\subsection{Influence of temperature and irradiation on PV operating}

For various values of the irradiation $\mathrm{G}$, and cells' temperature $\mathrm{T}$, the $\mathrm{I}-\mathrm{V}$ characteristics of the analysed PV panel are shown respectively in Figure 3 and Figure 4.
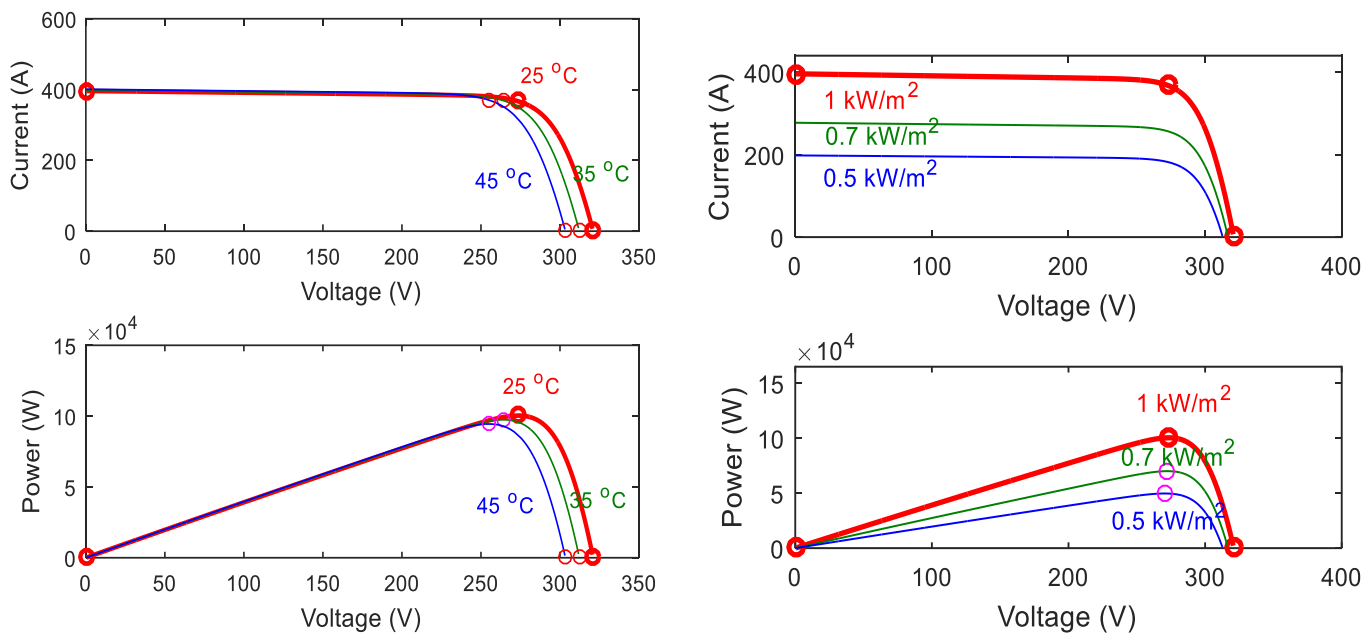

Figure 3. Influence of temperature with constant irradiation

Figure 4. Influence of irradiation with constant temperature

Depending on weather conditions, a PV generator connected to a load can operate in a large margin of current and voltage [22]. Figure 3 and Figure 4 show that the open circuit voltage Vco is increasing with the irradiation and decreasing slightly as the cell temperature increases. On the one hand, the short circuit current Isc is linearly depending on the ambient irradiation in direct proportion, while the open circuit voltage decrease slightly as the cell temperature increases. Therefore, the maximum power that could be generated by a PV system is slightly depending on the temperature and irradiation variations: the maximum power increases as the irradiation increases and vice versa, on the other hand a PV generator performs better for low temperature than raised one [12].

\subsection{The changes on temperature and irradiation}

It is known that temperature may be high despite the very little presence of any irradiation clouds. It is also known that the temperature change and the irradiation disposed relatively, the irradiation increases, more heat traditionally increased, and vice versa. 


\subsection{DC/DC boost converter}

A DC/DC converter the transfer of maximum energy from photovoltaic panel PV to load. A DC/DC converter is the interface that regulates the adaptation between the photovoltaic PV panel and the load to ensure our load closer to the MPP. Figure 5 shows the electrical circuit of the DC-DC converter Boost type. The Boost type converter is a voltage booster. In this converter, the value of the output voltage is always greater than that of the input. The inductance currently stores energy. When the switch is off (the ideal switch is open), the load receives this energy in addition to the GPV energy. In this type of converter, if we consider that Vin is the voltage of the GPV, $V_{\text {out }}$ is the voltage of the load and D is the duty cycle, then the relationship between these voltages and the load results in the (7):

$$
V_{\text {out }}=\frac{1}{(1-D)} V_{\text {in }}
$$

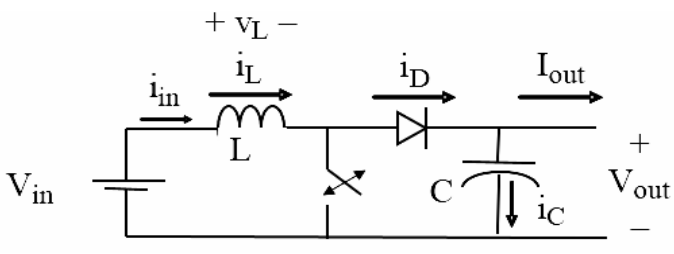

Figure 5. Boost converter DC/DC

\section{MPPT USING (P\&O) METHOD}

The principle of this type of control is based on the disturbance of the value of the voltage of the GPV and the observation of the behaviour of the resulting power [23]. Figure 6 shows the algorithm associated with a P\&O command. We note that we need two sensors to measure the power of the GPV as a function of time. Today, the $\mathrm{P} \& \mathrm{O}$ algorithm is widely used because of its simplicity and ease of implementation. In another sense, it has some disadvantages. For example, according to the characteristic curve $\mathrm{P}-\mathrm{V}$ of $\mathrm{PV}$ panel we can never reach $\Delta P=0$. Each time $\mathrm{V}$ increases or decreases the power will be changed which makes the implementation of the step $P p v_{k+1}=P p v_{k}$ in the algorithm without profit. This instability in the value of $\mathrm{P}$ will lead to instability around the optimal value of the power. However, this instability can be reduced by minimizing the increment value of the search algorithm.

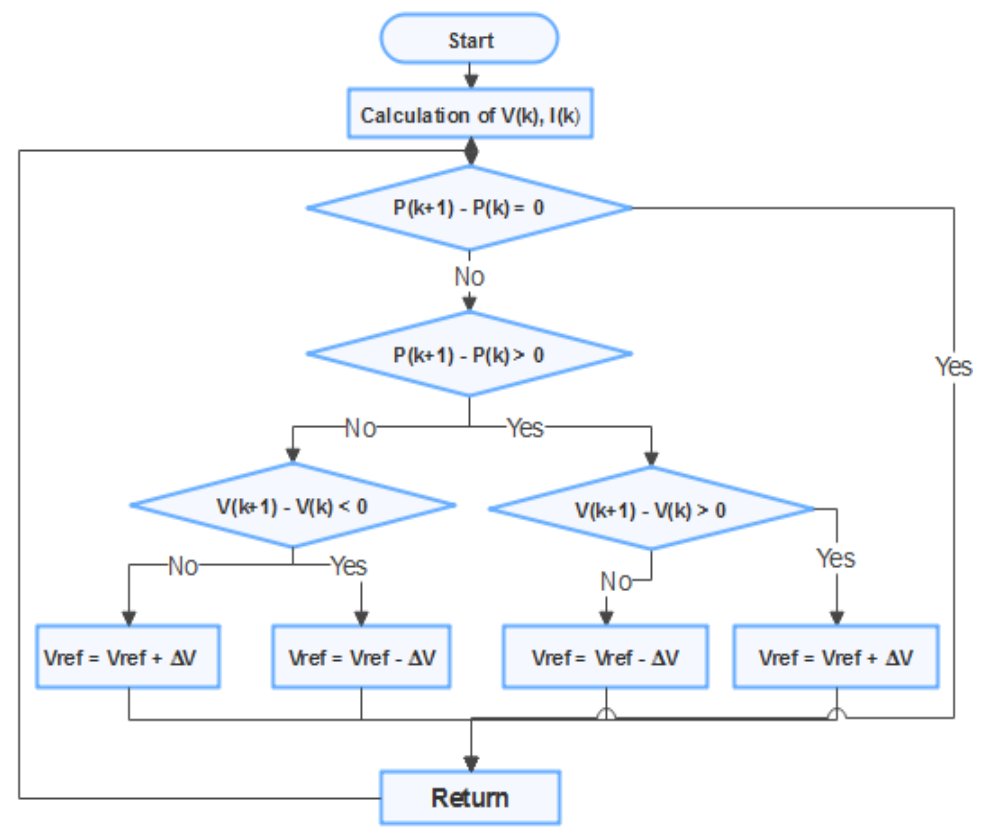

Figure 6. Flowchart of the algorithm of a $\mathrm{P} \& \mathrm{O}$ 


\section{NEURO-FUZZY MAXIMUM POWER POINT APPROACH}

The Neuro-Fuzzy approach consists of two stages; the first one is composed of multi-layered feed forwarded artificial neural network. The architecture composed of three layers: inputs, hidden and output layers while the second one is a fuzzy-rule-based.

Figure 7 show the proposed structure of the neuro-fuzzy approach. The hybrid model is composed of a neural model and a fuzzy logic controller.

The role of the neural model is to search for the region where MPP is located and the fuzzy controller helps to find and establish the MPP in that region. This approach consists the same MPPT Fuzzy logic controller, but we will decrease the pace of the duty cycle because we need a high degree of precision, on the one hand. On the other hand, the role of the neural network is to direct the controller to the region where the MPP is located. Therefore, we must first build the neural network that is preparing a learning base and learn the network, then implement this neural network in the control circuit, followed by fuzzy logic controller.

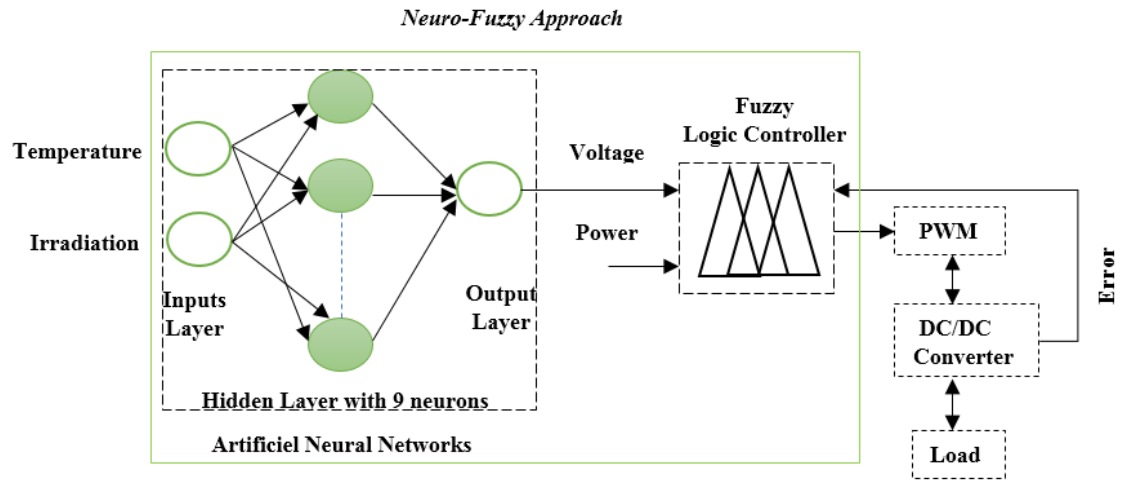

Figure 7. The proposed structure of the neuro-fuzzy approach

\subsection{The MPPT controller with ANN controller}

The new technique, which chooses the pursuit of the maximum power point, is the neural method. We will apply it to approximate the output, which is the voltage that corresponds to this power, as a function of irradiation changes, and temperature, is the tracking of the variation of the maximum power point. Where our system needs to evolve, quickly and efficiently.

\subsubsection{Mathematical modelling of an artificial neuron}

The mathematical model of an artificial neuron is illustrated in Figure 8. A neuron consists essentially of an integrator that performs the weighted sum of its inputs. The result $\mathrm{n}$ of this sum is then transformed by a transfer function $\mathrm{f}$, which produces the output $\mathrm{D}$ of the neuron. The $\mathrm{R}$ inputs of the neurons correspond to the vector $P=\left[p_{1} p_{2} \ldots \ldots p_{R}\right]^{T}$, while $W=\left[W_{l, 1} W_{l, 2} \ldots W_{l, R}\right]^{T}$, represents the vector of the weights of the neuron. The output $\mathrm{n}$ of the integrator is given by the following equation [15], [24]:

$$
n=\sum_{j=1}^{R}\left(w_{1, j} p_{j}\right)-b ; n=\left[\left(w_{1,1} p_{1}\right)+\left(w_{1,2} p_{2}\right)+\ldots .+\left(w_{1, R} p_{R}\right)\right]-b
$$

This can also be written in matrix form:

$$
\begin{aligned}
& n=\left(w^{T} p\right)-b \\
& a=f(n)=f\left(\left(w^{T} p\right)-b\right)
\end{aligned}
$$

This output corresponds to a weighted sum of weights and inputs minus what is called the bias $b$ of the neuron. The result $n$ of the weighted sum is called the activation level of the neuron. The bias $b$ is also called the activation threshold of the neuron. When the activation level reaches or exceeds the threshold $b$, then the argument of becomes positive (or zero). Otherwise, it is negative [15], [24]. There is an obvious analogy with biological neurons as shown in Table 2.

Under MATLAB/simulink, the role of the neural network is to direct the controller to the region where the MPP is located. Thus, it is necessary to build the neural network, i.e. to prepare a learning base and 
to learn the network, and then implement this neural network in the control circuit. The activation function makes it possible to define the internal state of the neuron according to its total input. There are several types of activation functions [25]. The activation function used in our neural network, which is a neural network multilayer is the sigmoid function for the hidden layer and the linear function for the output layer.

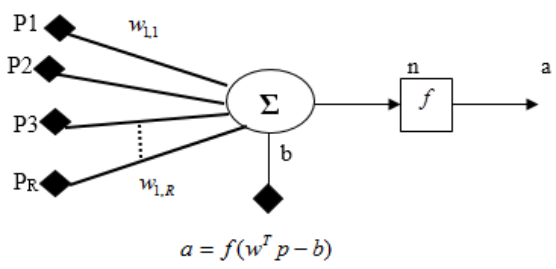

Figure 8. The artificial neuron models
Table 2. Analogy between the biological neuron and the formal neuron

\begin{tabular}{cl}
\hline $\begin{array}{c}\text { Biological } \\
\text { neuron }\end{array}$ & \multicolumn{1}{c}{ Formal neuron } \\
\hline $\begin{array}{c}\text { Synapse } \\
\text { Dendrites }\end{array}$ & $\begin{array}{l}\text { Weight of connections } \\
\text { Connections of other neurons to neuron } \mathrm{K}\end{array}$ \\
Axon & $\begin{array}{l}\text { Connections from neuron k to other neurons in the } \\
\text { network }\end{array}$ \\
Core & Activation function \\
\hline
\end{tabular}

\subsubsection{Multilayer network (multilayer perceptron MLP)}

An MLP is made up of several layers: an input layer, one or more hidden or intermediate layers, and an output layer. Two successive layers are fully connected, and all connections are unidirectional. In such a network, there are no connections between two neurons of the same layer. An MLP has therefore:

1) An input layer that receives the data to be processed;

2) One or more intermediate or hidden layers performing the specific processing of the network;

3) An output layer that presents the network responses.

The purpose of learning is to estimate network parameters by minimizing an error function. Learning is supervised. The error function thus represents the distance that exists between the calculated response of the network and its desired response. The learning consists in applying to the network pairs of inputs and outputs (desired outputs), and then applying a learning algorithm to modify the various parameters of the network. The learning algorithm used for this type of network is the gradient back propagation (GBP) [23].

The structure of the neural network used in the control system. This network has an input layer containing two inputs (Irradiation and Temperature), a hidden layer of 9 neurons and an output layer containing a single neuron (the voltage $\mathrm{V}$ ).

At the end of the learning phase, we obtain the final neural network implementation, which gives us a value very close to the exact value of the MPP. It admits as inputs the irradiation and temperature and as output, the voltage close to the MPP [26].

\subsection{The MPPT Controller with Fuzzy Logic}

A Fuzzy Logic Control (FLC) is used to work as an MPPT controller that tracks the optimal operating point of a PV panel. Fuzzy Logic Control is one of the most used techniques in different engineering challenges of its multi-rule-based characteristics [27]. Fuzzy logic control has a simple and clear procedure because exact mathematical modelling and technical quantities of a system are not required for this controller [28]. The fuzzy controller consists of three blocks: the first block fuzzification which numerical input variables $(V p v, P p v)$ are converted into linguistic variable $(E, D E)$ based on a membership function. The second block is devoted to inference rules, while the last block is the defuzzification for returning to the real domain $(D)$. This last operation uses the centre of mass to determine the value of the output [29]. Figure 9 shows the basic structure of the used MPPT Fuzzy controller [29].

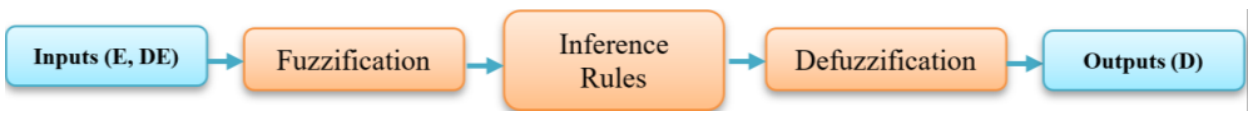

Figure 9. Block diagram of the FLC "SUPRIME" 
For the MPPT controller with fuzzy logic, the inputs are taken as a change in power and voltage as well. There is a block for calculating the error (E) and the change of the error (DE) at sampling instants k:

$$
\begin{aligned}
& E(k)=\frac{P_{p v}(k)-P_{p v}(K-1)}{V_{p v}(k)-V_{p v}(k-1)} \\
& D E=E(k)-E(k-1)
\end{aligned}
$$
at sample $\mathrm{k}$.

Where, $\operatorname{Ppv}(k)$ is the power delivered by PV panel and $V p v(k)$ is the terminal voltage of the module

Fuzzification: The resulting linguistic variables have been used for the MPPT fuzzy controller: PB (positive big), PS (positive small), ZE (zero), NS (negative small) and NB (negative big) for expressing the reel inputs and output variables. Figure 10a, Figure 10b and Figure 11 illustrate the membership functions of five fuzzy subsets for the input's variables $\mathrm{E}$ and $\mathrm{DE}$ and the output variable D.

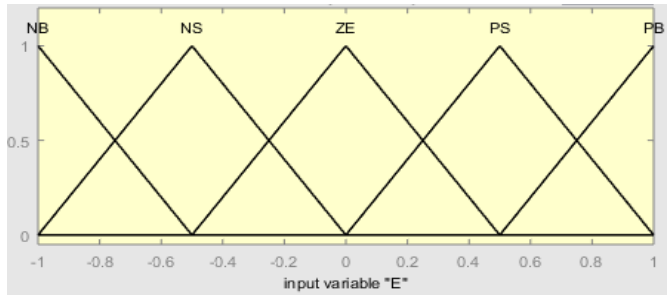

(a)

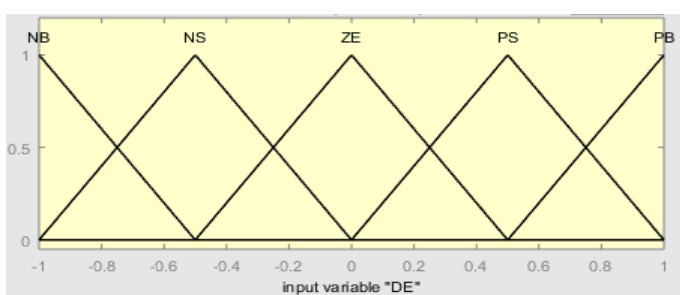

(b)

Figure 10. Membership functions (a) the error E (b) the change of the error DE

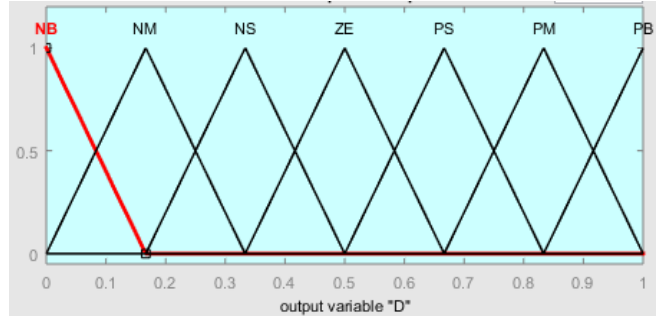

Figure 11. Membership functions of output variables D

Inference rules: Table 3 shows the rules table of the fuzzy controller where all inputs in the matrix are [E, DE] [30]. Defuzzification: The process of defuzzification converts the inferred fuzzy control action into a numerical value at the output (D) by making the combination of the outputs resulting from each rule. In this paper the centre of gravity defuzzifier, which is the most common one, is adopted. In the Figure 12 is shown the surface output $D=f(E, D E)$ of the MPPT controller.

Table 3. The fuzzy logic controller inference rule

\begin{tabular}{cccccc}
\hline DE & \multicolumn{5}{c}{ E } \\
& NB & NS & ZE & PS & PB \\
\hline NB & NB & NM & NS & PM & NB \\
NS & NB & NS & PS & ZE & NM \\
ZE & NM & ZE & PM & PS & NS \\
PS & NS & PS & PB & PM & ZE \\
PB & ZE & ZE & PB & PB & PS \\
\hline
\end{tabular}

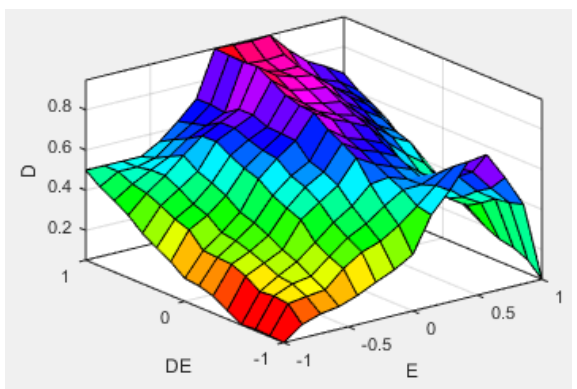

Figure 12. The surface $d=f(E, D E)$ of the MPPT controller output 


\section{SIMULATION RESULTS AND DISCUSSION}

Figure 1 represent the general diagram of the whole system, which composed of the PV array, block of DC/DC Boost converter, block of the novel neuro-fuzzy method and the resistive load. In the present study, a hybrid model, neuro-fuzzy, looking for to extract the maximum power for PV solar system in minimum time and a high degree of precision. The role of MPPT fuzzy logic controller is to choose the corresponding area region, which finds the MPP with decreasing the pace of the duty cycle. Then the neural network is to direct the controller to the region where the MPP is located. Several performance criteria are reported in the ANN literature as: the response time, learning base and learn the network. Thereby, the estimation performances of the neuro-fuzzy approach and the single ANN will be evaluated only in term of estimation time for extract the maximum power of PV solar system. The same thing was compared with the conventional algorithm $(\mathrm{P} \& \mathrm{O})$ regarding to the maximum power extracted under MATLAB/simulink. The theoretical and simulation results acquired with Neuro-Fuzzy, artificial neural network Controller and P\&O, in checking the MPP of the analysed PV module, for various values of solar irradiation G and cells' temperature $\mathrm{T}$ are given in Table 4 . Therefore, this table confirms that the neuro-fuzzy gives a quick response with stability around MPP than the conventional ANN and the P\&O. It also extracts the maximum power in short time with efficiency and pertinence. Nevertheless, this table expresses the most effort method between the conventional ANN and classical P\&O methods, these methods are limited around a small value especially of the maximum power with long time to response the $\mathrm{P} \& \mathrm{O}$ but the proposed Neuro-Fuzzy method overcome these limitations through a better definition of the model complexity based on the fuzzy rules. There are several performance criteria in the literature of the ANN method as mentioned before. In this study, after evaluated methods only in term of estimation. We have based on the calculation of the error between the measured values and the theoretical values of each method treated in this article P\&O, ANN and neuro-fuzzy approach. This calculation reveals the minimal error of the neuro-fuzzy approach compared to the other methods P\&O and ANN, on the one hand. On the other hand, we will calculate the efficiency to have the performance, speed and ability to respond to the PV system in a relevant and effective way.

Table 4. Simulation results of Pmax checking for different considered control

\begin{tabular}{cccccc}
\hline $\mathrm{G}\left[\mathrm{w} / \mathrm{m}^{2}\right]$ & $\mathrm{T}\left[{ }^{\circ} \mathrm{C}\right]$ & Perturb \& observe & Artificial neural networks & Neuro-fuzzy approach & Theoretical \\
\hline 1000 & 25 & 100,3 & 100,4 & 108 & 108,2 \\
900 & 22 & 90,53 & 91,06 & 97,61 & 97,80 \\
800 & 20 & 80,91 & 81,31 & 86,73 & 86,97 \\
700 & 19 & 70,66 & 71,13 & 75,69 & 75,81 \\
600 & 15 & 61,55 & 61,63 & 65,66 & 65,95 \\
500 & 12 & 51,58 & 51,61 & 55,94 & 56,95 \\
400 & 10 & 41,35 & 41,25 & 44,84 & 44,97 \\
\hline
\end{tabular}

Figure 13 and Figure 14 respectively shows the PV output Power for different considered control at STC weather conditions and low weather conditions. At STC weather conditions mean under the solar irradiation $\mathrm{G}=1000 \mathrm{~W} / \mathrm{m} 2$ and $\mathrm{PV}$ cells' temperature $\mathrm{TC}=25^{\circ} \mathrm{C}$, we can see that the proposed hybrid model Neuro-Fuzzy approach achieved the most accurate estimation comparing to the ANN and P\&O methods. At time $0.48 \mathrm{~s}$, the proposed hybrid model extracts the maximum power of the system equal Pout $=108 \mathrm{~W}$, while the ANN method extract Pout $=100,4 \mathrm{~W}$ and P\&O extract Pout $=100,3 \mathrm{~W}$ with oscillation around MPP. At low conditions, mean under the solar irradiation $\mathrm{G}=600 \mathrm{~W} / \mathrm{m} 2$ and $\mathrm{PV}$ cells' temperature $\mathrm{TC}=15^{\circ} \mathrm{C}$, the simulation results that the Neuro-Fuzzy hybrid model gives the best results of the maximum power at time $0.5 \mathrm{~s}$, although during evolution, the two MPPT methods are beginning before the hybrid model Neuro-Fuzzy. However, the last one contributes the best value of Power in short time with long steady regime without oscillation around the MPP.

Figure 15 presents the simulation output of the PV system (extracted power) during variation weather conditions using the Neuro-Fuzzy approach and the single ANN compared to conventional MPPT method P\&O. The Neuro-Fuzzy MPPT methodology accomplished better performances then the single ANN or the $\mathrm{P} \& \mathrm{O}$ algorithms that can fail to track the MPP or oscillates around it under rapidly changing climatic conditions. The performance of the MPPT can be detected according to the efficiency [31]-[34]. The efficiency calculated by the following (13):

$$
\text { Efficiency }=1-\frac{\text { Theorical } P_{\max }-\text { Measured }_{\max }}{\text { Theorical } P_{\max }}
$$




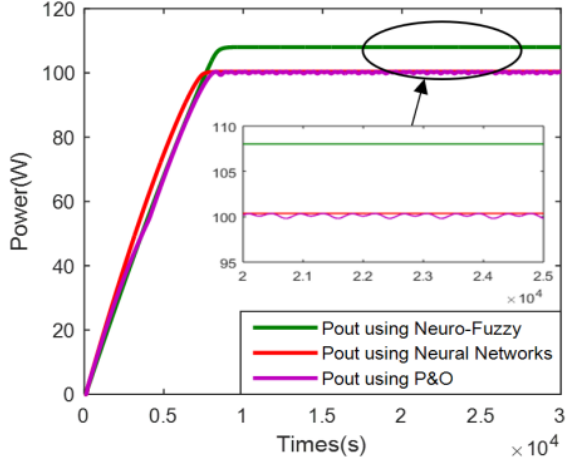

Figure 13. PV output Power for different considered control at $\mathrm{G}=1000 \mathrm{~W} / \mathrm{m}^{2}$ and $\mathrm{T}=25^{\circ} \mathrm{C}$

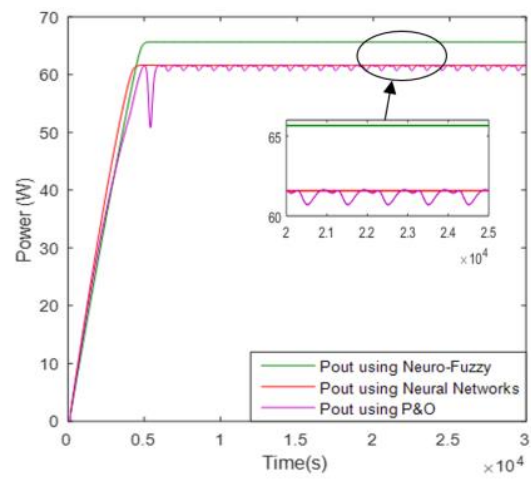

Figure 14. PV output Power for different considered control at $\mathrm{G}=600 \mathrm{~W} / \mathrm{m}^{2}$ and $\mathrm{T}=15^{\circ} \mathrm{C}$

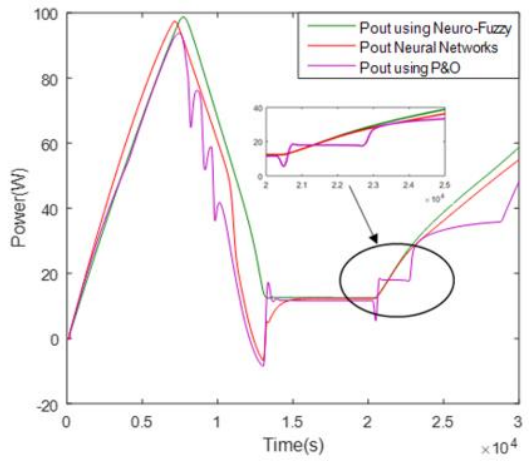

Figure 15. PV output Power for different considered control under variation of irradiation and temperature

The efficiency of P\&O, ANN and Neuro-Fuzzy controllers shows that the Neuro-Fuzzy controller can generate up to $99 \%$ of the actual maximum power compared to the ANN controller can generate up to 93\% and $\mathrm{P} \& \mathrm{O}$ can generate up to $92 \%$ of it [14] as shown in Figure 16. In fact, the proposed Neuro-Fuzzy approach-based method attained the highest power efficiency with $6 \%$ of extra-generated power comparing to the single ANN and more than $3 \%$ to the $\mathrm{P} \& \mathrm{O}$ algorithm because of its oscillations around the MPP.

To develop the new Neuro-Fuzzy controller approach, we relied on several articles in the literature among them [12], [30]. A kind of comparison in state of the art between our approach and two references [12], [30] in tabular format. In Table 5, a summary of the power efficiency between our approach and the reference [30], which is based on Toolbox ANFIS under MATLAB/simulink, in one hand. In the other hand, summarizes the error estimate between our approach and the reference [12]. This table shows that the power efficiency of the ANFIS method reaches $100 \%$ under the STC conditions and our approach reaches a value up to $99 \%$. Under the variations of atmospheric conditions, the power efficiency of our approach always remains up to $99 \%$, which shows the relevance of our neuro-fuzzy approach compared to the ANFIS method, which is already predefined in the MATLAB/simulink toolbox. After that, it illustrates that our new approach has higher percentages of errors for P\&O or ANN methods, compared to the comparative method. In other words, the percentage of the error is large in our approach that the error is minimal compared to the other reference.

Table 5. The percentage estimation neuro-fuzzy approach methods

\begin{tabular}{cccc}
\hline References & Efficiency (\%) & Error P\&O & Error ANN \\
\hline This study & $99.82,99.81,99.72,99.86,99.71$ & $3.74 \%$ & $6 \%$ \\
Chaouachi et al., 2010 & - & $2.73 \%$ & $5.86 \%$ \\
Aymen Jemaa et al. 2016 & $100,99.99,99.95,99.78,99.68$ & - & - \\
\hline
\end{tabular}




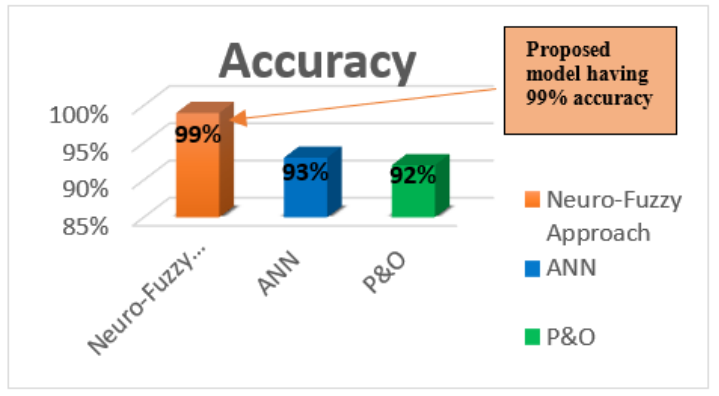

Figure 16. The efficiency of P\&O, ANN and Neuro-Fuzzy controllers

\section{CONCLUSION}

In this paper, a new MPPT methodology was applied to photovoltaic system based on a proposed Neuro-Fuzzy hybrid model. The whole system was simulated under MATLAB/simulink environment. In this study, we started by modelling the nonlinear system, which is the photovoltaic solar module, was demonstrated using the single-diode electrical model and simulated in different weather conditions. After that, learning about DC/DC converter has for role adapting the duty cycle to extract the maximum power, and transfer this energy from the photovoltaic solar to the load. Then, the most important part is the hybrid model: Neuro-Fuzzy approach. The developed Neuro-Fuzzy approach consists of two stages; the first one is composed of Inputs, one hidden layer with 9 neurons and one output feed forwarded ANN and the second one is a fuzzy-rule-based simulating under MATLAB/simulink. The proposed neuro-fuzzy approach showed the ability to faithfully emulate the dynamic and nonlinear behaviour of a photovoltaic generator under a large wide of climatic conditions. The completely photovoltaic solar system performance was tested with constant and several rapid irradiation and temperature variations. The accuracy of our proposed model Neuro-fuzzy approach can generate up to $99 \%$ of the actual maximum power, which is more than the other algorithm such as $\mathrm{P} \& \mathrm{O}$ and $\mathrm{ANN}$.

Therefore, the simulation results proved that the proposed Neuro-Fuzzy approach of the system performances, in terms of efficiency of power, precision and speed, was not degraded, as the MPPT dispositive was capable to track the maximum power point an optimal operating condition under any rapid changing meteoric conditions.

\section{REFERENCES}

[1] A. Chouder, F. Guijoan and S. Silvestre, "Simulation of fuzzy-based MPP tracker and performance comparison with perturb \& observe method," Revue des Energies Renouvelables, vol. 11, no. 4, pp. 577-586, 2008.

[2] C. Cabal, et al., "Adaptive Digital MPPT Control for Photovoltaic Applications," 2007 IEEE International Symposium on Industrial Electronics, 2007, pp. 2414-2419, DOI: 10.1109/ISIE.2007.4374985.

[3] S. Lalouni, D. Rekioua, T. Rekioua, and E. Matagne, "Fuzzy logic control of stand-alone photovoltaic system with battery storage," Journal of Power Sources, vol. 193, no. 2, pp. 899-907, 2009, DOI: 10.1016/j.jpowsour.2009.04.016.

[4] M.A. Awadallah, "Identification of partial shading in solar panels using genetic algorithms, simulated annealing and particle swarm optimization," Int. J. Renewable Energy Technology, vol. 7, no. 2, pp. 125-147, 2016, DOI: 10.1504/IJRET.2016.076088.

[5] I. Glasner and J. Appelbaum, "Advantage of Boost vs. Buck Topology for Maximum Power Point Tracker in Photovoltaic Systems," Proceedings of 19th Convention of Electrical and Electronics Engineers in Israel, 1996, pp. 355-358, DOI: 10.1109/EEIS.1996.566988.

[6] M. Veerachary and N. Yadaiah, "ANN Based Peak Power Tracking for PV Supplied DC Motors," Solar Energy, vol. 69, no. 4, pp. 343-354, 2000, DOI: 10.1016/S0038-092X(00)00085-2.

[7] E. Mujadi, "PV Water Pumping with A Peck-Power Tracker Using a Simple Six Step Square-Wave Inverter," IEEE Transactions on Industry Applications, vol. 33, no. 3, pp. 714-721, 1997, DOI: 10.1109/28.585862.

[8] B.K. Bose, P. M. Szczesny and R. L. Steigerwald, "Microcomputer Control of a Residential Photovoltaic Power Conditioning System," IEEE Transactions on Industry Applications, vol. IA-21, no. 5, pp. 1182-1191, 1985, DOI: 10.1109/TIA.1985.349522.

[9] J.M. Enrique, J.M. Andújar, and M.A. Bohórquez, "A reliable, fast and low-cost maximum power point tracker for photovoltaic applications,” Solar Energy, vol. 84, no. 1, pp. 79-89, 2010, DOI: 10.1016/j.solener.2009.10.011.

[10] D.P. Hohm and M.E. Ropp, "Comparative study of maximum power point tracking algorithms," Progress in Photovoltaic: Research and Applications, vol. 11, no. 1, pp. 47-62, 2003, DOI: 10.1002/pip.459. 
[11] V. Salas, E. Olías, A. Barrado, and A. Lázaro, "Review of the maximum power point tracking algorithms for standalone photovoltaic systems," Solar Energy Materials \& Solar Cells, vol. 90, no. 1, pp. 1555-1578, 2006, DOI: 10.1016/j.solmat.2005.10.023.

[12] A. Chaouachi, Rashad M. Kamel, and Ken Nagasaka, "A novel multi-model ANN-Fuzzy approach-based MPPT for three-phase grid-connected photovoltaic system," Journal of Solar Energy, vol. 84, no. 12, pp. 2219-2229, 2010, DOI: 10.1016/j.solener.2010.08.004.

[13] A. Mellit and S.A. Kalogirou, "Artificial intelligence techniques for photovoltaic applications: a review," Progress in Energy and Combustion Science, vol. 34, no. 5, pp. 574-632, 2008, DOI: 10.1016/j.pecs.2008.01.001.

[14] C. Ben Salah and M. Ouali, "Comparison of fuzzy logic and neural network in maximum power point tracker for PV systems," Electric Power Systems Research, vol. 81, no. 1, pp. 43-50, 2011, DOI: 10.1016/j.epsr.2010.07.005.

[15] T. Rouibah, "Application de l'intelligence artificielle au problème de la stabilité transitoire des réseaux électriques," Thesis magister Ph.D, Sharif University of Technology Téhéran, IRAN, 1998.

[16] A. Jemaa, Z. Ons, M. M. Nejib and A. Craciunescu, "Maximum Power Point Tracking of Photovoltaic Modules: Comparison of Fuzzy Logic and Artificial Network Controllers' Performances," 2016 Third International Conference on Mathematics and Computers in Sciences and in Industry (MCSI), 2016, pp. 89-93, DOI: 10.1109/MCSI.2016.027.

[17] Y. Soufi, Mohcene Bechouat, and Sami Kahla, "Fuzzy-PSO controller design for maximum power point tracking in photovoltaic system," International Journal of Hydrogen Energy, vol. 42, no. 13, pp. 8680-8688, 2017, DOI: 10.1016/j.ijhydene.2016.07.212.

[18] Z. Xuecheng and Z. Yuhong, "Control method of photovoltaic maximum power point tracking based on the theory of fuzzy," 2nd International Conference on Electronic \& Mechanical Engineering and Information Technology, 2012, pp. 2002-2005, DOI: 10.2991/emeit.2012.444.

[19] L.A. Zadeh, "Fuzzy sets," Information and Control, vol. 8, no. 3pp. 338-353, 1965, DOI: 10.1016/S00199958(65)90241-X.

[20] L.A Zadeh, "Outline of a new approach to the analysis of complex systems and decision processes," IEEE Transactions on Systems, Man, and Cybernetics, vol. SMC-3, no. 1, pp. 28-44, 1973, DOI: 10.1109/TSMC.1973.5408575.

[21] M.G. Villalva, J. R. Gazoli and E. R. Filho, "Comprehensive approach to modeling and simulation of photovoltaic arrays," IEEE Transactions on Power Electronics, vol. 24, no. 5, pp. 1198-1208, May 2009, DOI: 10.1109/TPEL.2009.2013862.

[22] G.M. Masters, Renewable and Efficient Electric Power Systems, Wiley-IEEE Press, 2004.

[23] B. Kanj, "Techniques Intelligentes pour la Poursuite du Point de Puissance Maximale d'un Système Photovoltaïque," These magister Phd, Université Libanaise Faculté de Génie Branche III, 2012.

[24] M. Parizeau, "Réseaux de neurones," 2004. [Online]. Available : http://seborga1.free.fr/RNF.pdf

[25] R. Tahar, "Application de l'intelligence artificielle au problème de la stabilité transitoire des réseaux électriques," These magister Phd, ÉCOLE DE TECHNOLOGIE SUPÉRIEURE UNIVERSITÉ DU QUÉBEC, 2005.

[26] A. Harendi, "Modélisation et simulation d'un système photovoltaïque," These Master, Universite kasdi merbah ouargla, Faculté des Sciences Appliquées. 2014.

[27] I. Kashif, S.S. Abdullah, S.M. Ayob and Z. Salam, "Single input fuzzy logic controller for unmanned underwater vehicle," J Intell Robot Syst, vol. 59, pp. 87-100, 2010, DOI: 10.1007/s10846-010-9395-x.

[28] C. Chian-Song, "T-S Fuzzy maximum power point tracking control of solar power generation systems," in IEEE Transactions on Energy Conversion, vol. 25, no. 4, pp. 1123-1132, 2010, DOI: 10.1109/TEC.2010.2041551.

[29] M. Hatti, "Contrôleur flou pour la poursuite du point de puissance maximum d'un système Photovoltaïque," sème Conférence des Jeunes Chercheurs en Génie Electrique (JCGE'08), Lyon. 2008.

[30] J. AYMEN, Z. ONS, A. CRĂCIUNESCU, and M. POPESCU, "Comparison of Fuzzy and Neuro-Fuzzy approach Controllers for Maximum Power Point Tracking of Photovoltaic Modules," International Conference on Renewable Energies and Power Quality (ICREPQ'16), 2016, pp. 2172-038, DOI: 10.24084/repqj14.465.

[31] A.B.G. Bahgat, N.H. Helwa, G.E. Ahmad, and E.T. El Shenawy, "Maximum power traking controller for PV systems using neural networks," Renewable Energy, vol. 30, no. 8, pp. 1257-1268, 2005, DOI: 10.1016/j.renene.2004.09.011.

[32] T. Kawamura, et al., "Analysis of MPPT characteristics in photovoltaic power system," Solar Energy Materials and Solar Cells, vol. 47, no. 1-4, pp. 155-165, 1997, DOI: 10.1016/S0927-0248(97)00036-6.

[33] C. Larbes, S.M. Aït Cheikh, T. Obeidi, and A. Zerguerras, "Genetic algorithms optimized fuzzy logic control for the maximum power point tracking in photovoltaic system," Renewable Energy, vol. 34, no. 1, pp. 2093-2100, 2009, DOI: 10.1016/j.renene.2009.01.006

[34] A.D. Karlis, T.L. Kottas and Y.S. Boutalis, "A novel maximum power point tracking method for PV systems using fuzzy cognitive networks (FCN)," Electric Power Systems Research, vol. 77, no. 3-4, pp. 315-327, 2007, DOI: 10.1016/j.epsr.2006.03.008. 


\section{BIOGRAPHIES OF AUTHORS}
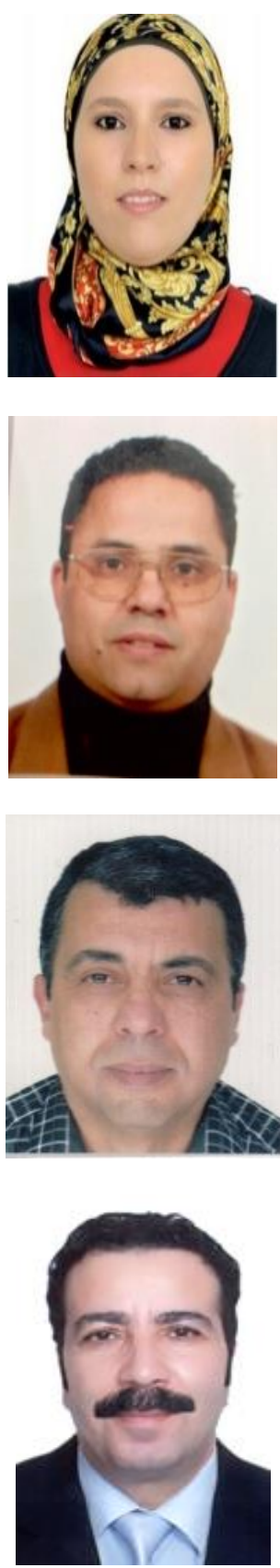

Aouatif Ibnelouad was born in 1987, received the Engineer' degree of state in Electrical Engineering and Telecommunication from the Faculty of Science and Technology of Marrakech (FSTM) Morocco. She is currently a Ph.D. student at the Electrical Systems and Telecommunications Laboratory, Cadi Ayyad University of Marrakech, Morocco. His research focuses on intelligent control of nonlinear systems such as photovoltaic systems, implementation, automatic and industrial data processing.

Abdeljalil El Kari obtained his doctorate thesis in 1993 form University of Bordeaux I. Since 1994, he is a professor at the Faculty of Science and Technology of Marrakesh, responsible of electrical engineering master. In 2002, he obtained the $\mathrm{PhD}$ degree from Cadi Ayyad University and Reims Champagne-Ardenne University. He is a researcher member of the Electric Systems and Telecommunications Laboratory. His research interests concern automatic, robotics and artificial Intelligence.

Hassan AYAD obtained his doctorate thesis in 1993 form University of Le Havre FRENSH. Since 1993, he is a professor at the Faculty of Science and Technology of Marrakesh, Responsible of the Physical department. In 2007, he obtained the PhD degree from Cadi Ayyad University. He is a researcher member of the Electric Systems and Telecommunications Laboratory. He has participated in and led several research and cooperation projects and he is the author of more than 20 international communications and publications.

Mostafa MJAHED received his 3ème cycle Doctorate in HEP from the University of Clermont Ferrand, France, in 1987, and a Ph.D. degree in Control and Artificial Intelligence from the University of Cadi Ayyad, Marrakech, in 2003. In 1989, he joined the Ecole Royale de l'Air, Marrakech, Morocco, as an associate professor in the Department of Mathematics and Systems. From 2003, he has been a professor in the same institute and department. His current research interests are conventional, and AI based flight control, pattern recognition and classification (GA, PSO, NN). 